\title{
Studi Fenomenologi Budaya Keselamatan Pasien Dari Perspektif Kepala Ruang Instalasi Rawat Inap di RSUD Raden Mattaher Jambi
}

\author{
Afridawaty $\mathbf{M J}^{1 *}$, Meri Neherta ${ }^{2}$, Fitra Yeni ${ }^{3}$ \\ ${ }^{1,2,3}$ Program Studi Magister Keperawatan, Fakultas Keperawatan, Universitas Andalas, \\ Jl. Limau Manis, Kecamatan Pauh, Sumatera Barat 25163, Indonesia \\ *Correspondence email: afrida.telanai84@gmail.com
}

\begin{abstract}
Abstrak. Budaya keselamatan pasien merupakan kunci untuk mendukung pencapaian perbaikan dalam keselamatanva pasien kepala ruangan sebagai manajer operasional yang bertanggung jawab untuk menghasilkan layanan yang berkualitas untuk mengelola semua sumber daya di unit perawatan, terutama dalam pengelolaan keselamatan pasien.Penelitian bertujuan untuk menggali secara mendalam keselamatan pasien budaya dari perspektif kepala ruangan. desain penelitian adalah metode fenomenologi deskriptif, pengumpulan data dengan wawancara mendalamdan catatan lapangan. Partisipan dalam penelitian ini diambil dengan teknik purposive sampling denganh tujuh partisipan. analisis data menggunakan metode Collaizi. Hasil penelitian ini mengidentifikasi tujuh tema, yaitu (1) pengalaman budaya keselamatan pasien, (2) dimensi budaya keselamatan pasien, (Berdasarkan hasil yang diperoleh oleh kepala ruangan perlu memahami fungsi manajemen dalam pengelolaan keselamatan pasien dan meningkatkan pengawasan.
\end{abstract}

Kata kunci: Kepala ruangan; perspektif; budaya keselamatan pasien

\begin{abstract}
Patient safety culture is the key to support the achievement of improvement in the safety of the patient's head of the room as the operational manager responsible for delivering quality services to manage all the resources in Care unit, especially in the management of patient safety. Research aims to delve deeply into the safety of cultural patients from a room head perspective. Design research is a method of descriptive phenomenology, data collection with interviews Postamand field records. Participants in this study were taken with purposive sampling techniques with seven participants. Data analysis using Collaizi method. The results of this study identified seven themes, namely (1) Experience the culture of patient safety, (2) Dimension of patient safety culture, (based on results obtained by the head of the room need to understand the function of management in safety management Patients and improve supervision.
\end{abstract}

Keywords: Head of the room; perspective; patient safety culture

\section{PENDAHULUAN}

Kepala ruangan merupakan tenaga perawat yang diberi tugas memimpin satu ruang rawat, dan bertanggung jawab terhadap pemberian asuhan keperawatan, yang berperan sebagai first line manager di sebuah rumah sakit, yang diharapkan mampu melaksanakan fungsi manajemen keperawatan (Sitorus \& Panjaitan, 2011). Hasil Penelitian (Nordin et al, 2013) membuktikan bahwa budaya keselamatan pasien yang kuat akan memperpendek lama hari rawat, kemauan pengobatan, pelaporan kesalahan pasien jatuh lebih sedikit, dan tingkat komplikasi di rumah sakit lebih rendah. Selain itu, budaya keselamatan pasien akan mengurangi biaya finansial yang diakibatkan oleh kejadian keselamatan pasien serta melindungi tenaga kesehatan dari tuntutan pasien ketika terjadi kesalahan medis (Calado \& Santos, 2014).

Peran dan fungsi kepala ruangan diruang rawat dalam fungsi manajemen keperawatan antara lain perencanaan, pengorganisasian, pengaturan ketenagaan, pengarahan, pengawasan dan pengendalian mutu yang merupakan satu siklus yang saling berkaitan satu sama lain (Marquis \& Huston. 2012). Kepala ruangan sebagai manajer operasional, yang memimpin secara langsung, dalam mengelola seluruh sumber daya di unit perawatan untuk menghasilkan pelayanan yang bermutu, dan dituntut untuk menjadi motor penggerak, bagi sumbersumber dan alat-alat dalam suatu organisasi melalui pengambilan keputusan, penentuan kebijakan dan menggerakkan orang lain untuk mencapai tujuan organisasi (Curtis \& O'Connell, 2011).

Keselamatan pasien telah menjadi isu dunia yang perlu mendapat perhatian bagi pelayanan kesehatan. Keselamatan pasien merupakan prinsip dasar dari pelayanan kesehatan, yang memandang bahwa keselamatan merupakan hak setiap pasien dalam menerima pelayanan kesehatan (Kemenkes RI, 2011). Keselamatan pasien merupakan suatu sistem yang difokuskan untuk meningkatkan mutu pelayanan kesehatan. Fokus tentang keselamatan pasien didorong oleh masih tingginya angka kejadian tidak diharapkan (KTD) di rumah sakit baik secara global maupun nasional (KKP-RS, 2015). RSUD Raden Mattaher Jambi merupakan rumah sakit tipe B pendidikan yang memiliki 14 ruang rawat inap, dengan 384 kapasitas tempat tidur yang merupakan pusat rujukan kesehatan di wilayah Provinsi Jambi, dan telah mendapatkan sertifikat lulus akreditasi tingkat paripurna pada tahun 2016. BOR (Bed Occupation Rate) pada tahun 2015 59,87\% dan tahun $201659,92 \%$, dilihat dari data tersebut bahwa nilai BOR 
Afridawati MJ et al, Studi Fenomenologi Budaya Keselamatan Pasien Dari Perspektif Kepala Ruang Instalasi Rawat Inap di RSUD Raden Mattaher Jambi

masih berada di bawah standar (70-85\%), dengan ratarata lama hari rawat inap 5,31 hari (RSUD Raden Mattaher, 2016).

Fenomena yang terlihat di Rumah Sakit Raden Mattaher Jambi menunjukkan bahwa Budaya keselamatan pasien oleh kepala ruangan belum sepenuhnya menerapkan budaya keselamatan pasien secara optimal. Dari penelitian yang ada, belum ada penelitian yang spesifik mengarah kepada budaya keselamatan pasien dari sudut pandang kepala ruangan, sehingga perlu diketahui tentang budaya keselamatan pasien dari perspektif kepala ruangan.

\section{METODE}

Penelitian ini menggunakan pendekatan fenomenologi yang bertujuan untuk mendapatkan gambaran/deskriptif tentang suatu pengalaman hidup yang dilihat dari sudut pandang orang yang diteliti, untuk memahami dan menggali pengalaman hidup yang dijalani (Moleong, 2010). Jenis Penelitian Fenomenologi adalah Fenomenologi deskriptif yang dikembangkan oleh Husserl, dimana fenomenologi deskriptif menekankan tentang pengalaman manusia, seperti; pengalaman kehidupan sehari-hari, menjelaskan hal-hal yang dialami seperti mendengar, melihat, kepercayaan, perasaan, mengingat, mengambil keputusan, menilai dan bertindak (Moleong, 2010). Populasi dalam penelitian ini KepalaRuangan Perawatan di rumah sakit Raden Mattaher Provinsi Jambi berjumlah 7 orang.

Teknik Pengambilan Sampel dalam penelitian ini menggunakan dengan teknik Colaizzi dengan metode puposive samping

\section{HASIL DAN PEMBAHSAN}

Dalam penelitian ini ditemukan dua tema yaitu 1) pengalaman mengenai budaya keselamatan pasien, 2) dimensi budaya keselamatan pasien

Tema 1: Pengalaman mengenai budaya keselamatan pasien

Pengalaman mengenai budaya keselamatan pasien dijabarkan dalam 3 sub tema yaitu penilaian pelayanan kesehatan, pemberian asuhan yang aman dan keselamatan pasien sebagai prioritas

a. Kategori penilaian terhadap pelayanan kesehatan diungkapkan partisipan sebagai berikut :

“ .........keselamatan pasien termasuk dalam pelayanan bagaimana penilaian rumah sakit itu"( $\mathrm{P} 1)$ “...........pasien yang masuk ke tempat kita, kita lakukan pelayanan sesuai dengan standar keselamatan pasien"( $(\mathrm{P} 2)$

b. Kategori melindungi pasien dan petugas kesehatan diungkapkan oleh partisipan sebagai berikut :

“...........Keselamatan pasien berarti memang pasien itu memang harus kita lindungi" (P2)

"..........untuk melindungi pasien dan petugas jangan sampai kita niatnya membantu pasien tapi malah membuat masalah sehingga terjadi tuntutan dikemudian hari $(\mathrm{P} 4)$

c. Kategori keselamatan pasien merupakan sesuatu yang sangat penting diungkapkan oleh sebagian besar partisipan yang dinyatakan sebagai berikut :

".........Itu sangat penting, .........sangat-sangat penting karena menyangkut keselamatan pasien itu sendiri' dan menyangkut kewenangan hukum (P1)

" Keselamatan pasien sangat penting karena kita perawat sangat bertanggung jawab terhadap keselamatan pasien" (P3)

\section{Tema 2: dimensi budaya keselamatan pasien}

Dimensi budaya keselamatan pasien di jabarkan dalam 5 sub tema yaitu, komunikasi pemebalajaran terus menerus kerja sama tim, respon tidak menyalahkan dan pelaporan insiden keselamatan.

a. Sub tema komunikasi dibentuk dengan kategori diskusi mengenai keselamatan pasien, hubungan saling terbuka dan melibatkan pasien dan keluarga. Berikut ungkapan partisipan dengan kategori diskusi : "......Mengadakan diskusi pertemuan untuk membahas permasalahan yang menyangkut keselamatan pasien" (P2)

"......Kita ambil kasus kemudian mendiskusikannya" (P4)

“......Kita cari lemahnya dimana itu yang harus diperbaiki” (P5)

“......Dengan tim angka kejadian tetap dikasih tau dan nanti dibahas dimana salahnya (P6)

b. Sub tema pembelajaran terus menerus dilakukan oleh kepala ruangan dengan kategori belajar dari kesalahan dan peningkatan kompetensi. Kategori peningkatan kompetensi diungkapkan oleh partisipan sebagai berikut:

“.......Tanpa menyalahkan dia sadar, dan buat lainnya yang bahwa lain kali harus dicek dulu, jadi bekerja sesuai standar jadi kita kembali lagi mempelajari SPO supaya tidak terjadi lagi kesalahan yang sama"(P4)

“......Apa masalahnya,kelemahannya dimana itu yang harus diperbaiki (P5)

“.......kalau adek kita perawat pelaksana melakukan kesalahan supaya ruangan yang lain tidak terjadi kesalahan yang sama $(\mathrm{P} 7)$

c. Sub tema kerja sama dilakukan dengan saling mengingatkan antara sesama perawat, dokter, dan koordinasi dengan berbagai unit yang terkait dengan keselamatan pasien. Kategori saling mengingatkan satu:

“......Kalau dokter dan perawat saling mengingatkan"

"......Saling mengingatkan kembali terus-menerus kepada perawat pelaksana" (P3)

“..... Saling mengingatkan sesama perawat"(P6)

“ ......Dokter juga mengingngatkan kalau pasien memakai obat-obat yang kemungkinan resiko 
Afridawati MJ et al, Studi Fenomenologi Budaya Keselamatan Pasien Dari Perspektif Kepala Ruang Instalasi Rawat Inap di RSUD Raden Mattaher Jambi

jatuh.jadi dokter mengingtakan kepada perawat" (P7)

d. Sub tema tidak menyalahkan dibentuk dengan tiga kategori bebas blooming, tidak menghukum atau mencari kesalahan, dan kesalahan bukan hanya pada individu. Respon tidak menyalahkan dengan kategori tidak mencari kesalahan/menghukum diungkapkan hampir seluruh partisipan sebagai berikut :

".........tidak mencari kesalahan kalaupun memang ada kejadian ini apa masalahnya lemahnya dimana itu yang harus diperbaiki'(P5)

“..........Jadi kita dapat insiden apalagi ada pasien jatuh biasanyakan kalau staf itu awalnya tidak berani melapor, kita budayakan mereka berani lapor tanpa menyalahkan"(P4)

e. Sub tema pelaporan dengan kategori pelaporan insiden dilaporkan berdasarkan jumlah kejadian, menggunakan form pelaporan insiden yang disediakan oleh rumah sakit serta mengevaluasi laporan kejadian pada setiap rapat bulanan sebagai berikut :

“...disini kita ada merekap pelaporanpelaporan.....dilaporkan, jika apabila terjadi sesuatu kepada pasien misalnya pasien jatuh, salah pemberian obat atau tranfusi"(P1)

".........kita harus membuat laporan, misalnya jika ada insiden" (P4)

"........jadi kita membuat suatu laporan khusus misalnya kejadian dalam ".sasaran keselamatan pasien." (P3)

'............insiden apapun insiden yang mempengaruhi keterlambatan pelayanan kita harus buat laporan" (P2)

\section{Pembahasan}

\section{Persepsi budaya keselamatan pasien}

Hasil penelitian partisipan mengungkapkan bahwa budaya keselamatan pasien merupakan hal yang sangat penting karena dapat memberikan keselamatan kepada pasien dan petugas kesehatan, keselamatan pasien juga merupakan hal yang diutamakan. Keselamatan pasien menjadi perhatian khusus saat ini karena semakin meningkatnya pengetahuan masyarakat, maka tuntutan untuk memperoleh pelayanan yang berkualitas juga semakin meningkat dan semakin sadarnya masyarakat akan pentingnya keselamatan saat mendapatkan pelayanan kesehatan. Keselamatan pasien sebagai prioritas di RSUD Raden Mattaher didukung oleh pandangan kepala bidang keperawatan mengenai budaya keselamatan pasien yang menyatakan bahwa keselamatan pasien menjadi prioritas utama yang harus dilaksanakandan terus ditingkatkan karena akan berguna bagi pemberi pelayanan itu sendiri salah satunya jajaran keperawatan sendiri sehingga pasien merasa aman datang ke rumah sakit
Hasil ini konsisten dengan Departemen Kesehatan (Depkes RI, 2015), bahwa keselamatan pasien adalah prioritas utama untuk rumah sakit yang terkait dengan keselamatan pasien, petugas keselamatan dan kesehatan pekerja, keselamatan bangunan dan peralatan di rumah sakit yang berdampak pada keselamatan pasien dan petugas.

Melalui penelitian ini juga mengungkapkan bahwa budaya keselamatan pasien adalah kualitas kesehatan dan meningkatkan kepercayaan publik. Hal ini sesuai dengan KKP-RS $20 \quad 15$ bahwa rumah sakit meningkatkan kualitas layanan yang diperlukan untuk menerapkan standar keselamatan pasien, dengan meningkatkan keselamatan pasien rumah sakit, diharapkan kepercayaan masyarakat dalam perawatan rumah sakit dapat ditingkatkan.

Berdasarkan hasil tersebut, dalam hal ini peneliti memiliki pandangan bahwa perspektif budaya keselamatan pasien merupakan pengalaman subjektif individu dirinya sebagai kepala ruangan. Setiap kamar memiliki kepala persepsi masing-masing untuk memahami budaya keselamatan pasien. Persepsi ruang kepala akan berbeda pada setiap orang. Faktor karakteristik individu seperti umur, jenis kelamin, tingkat pengetahuan, faktor situasional, dan karya desain akan mempengaruhi persepsi seseorang.

\section{Pasien Budaya Keselamatan Dimensi}

Hasil penelitian ini mengungkapkan bahwa dimensi budaya keselamatan pasien yang dibangun partisipan dalam melaksanakan keselamatan pasien adalah komunikasi, pembelajaran terus menerus, kerjasama, respon tidak menyalahkan dan pelaporan insiden keselamatan pasien. Hal ini tidak sesuai dengan AHRQ (Agency for Healthcare Research and Quality) budaya keselamatan pasien terdiri atas 12 dimensi yaitu kerjasama dalam unit, kerjasama antar unit, dukungan manajemen, pembelajaran organisasi, persepsi keselamatan pasien, tindakan promotif manajer, respon tidak menghukum, umpan balik dan komunikasi, komunikasi terbuka, pelaporan kejadian, staffing, handoff dan transisi. Hasil ini menunjukkan bahwa dari 12 dimensi budaya keselamatan hanya empat dimensi budaya keselamatan pasien yang sudah diungkapkan oleh partisipan berdasarkan tingkat unit yaitu komunikasi, pembelajaran terus menerus, kerja tim, respon tidak menyalahkan dan 1 aspek outcome dalam budaya keselamatan pasien yaitu pelaporan. Hasil penelitian ini tidak sejalan dengan NPSA bahwa dimensi budaya keselamatan pasien adalah kepemimpinan, kerja tim, komunikasi, beban kerja dan sistem keamanan (National Pasien Safety Agency, 2009), sedangkan dalam penelitian Sammer mengidentifikasi enam sub culture dari budaya keselamatan pasien adalah leadership, communication, teamwork, justice, learning, 
evidence based care, dan patient centered care (Sammer et al, 2010).

\section{SIMPULAN}

Berdasarkan hasil penelitian ini, dapat disimpulkan bahwa pengalaman kepala ruangan mengenai budaya keselamatan pasien yaitu keselamatan pasien sebagai prioritas, pemberian asuhan yang aman, dan penilaian pelayanan kesehatan di rumah sakit. Dimensi budaya keselamatan pasien dalam membangun budaya keselamatan adalah pembelajaran terus menerus, komunikasi, kerja sama tim, respon tidak menyalahkan dan pelaporan insiden keselamatan

\section{DAFTAR PUSTAKA}

Calado Monteiro, J.A. \& Santos Natário, M.M., (2014). Safety Culture in the Surgical Services: Case study. Tékhne, 12(1-2), pp.37-47.

Curtis, Elizabeth \& O'Connell, R., (2011). Essential Leadership Skills for Motivating and Developing Staff. Journal Nursing Management 18(5).32-35

Data Rekam Medik RSUD Raden Mattaher Jambi, 2016

Departemen Kesehatan RI (2015), Panduan Nasional Keselamatan Pasien Rumah Sakit (Patient Safety). Jakarta : Depkes RI

Kemenkes Menteri Kesehatan Republik Indonesia (2011). Peraturan Menteri Kesehatan Republik Indonesia Nomor 1691/Menkes/Per/VIII/2011 tentang Keselamatan Pasien Rumah Sakit: Jakarta

Komite Keselamatan Pasien Rumah Sakit (KKP-RS) (2015), Pedoman Pelaporan Insiden Keselamatan Pasien (IKP), Jakarta: KKPRS

Marquis, B.L \& Huston, C., (2012). Leadership Roles and Management Function in Nursing; Theory and Application 7 th., Philadelphia: Lippincott Williams \& Wilkins.

Moleong, L.J (2010), Metodologi Penelitian Kualitatif. Edisi Revisi. Bandung; PT Remaja Rosdakarya.

National Pasien Safety Agency, (2009). Manchester Patient Safety Framework (MapSaf) Manchester University of Manchester

Nordin, A., Wilde-Larsson, B., et al., (2013). Swedish Hospital Survey on Patient Safety CulturePsychometric properties and health care staff's perception. Open Journal of Nursing, 3(December), pp.41-50.

Sammer, EC, Lyens, K, Karan P, Lackan N 2010. What is Patient Safety Culture? A Review of the Literature. Jounal of Nursing Scholarship : 42-2 hal 156-165

Sitorus, R \& Panjaitan, R., 2011. Manajemen Keperawatan: Manajemen Keperawatan di Ruang Rawat, Jakarta: Sagung Seto. 